\title{
Pertumbuhan Tunas Sansevieria trifaciata Prain 'Laurentii' pada Beberapa Komposisi Media Tanam dan Konsentrasi GA3
}

\section{Shoots Growth of Sansevieria trifaciata Prain 'Laurentii' in some Growing Media Composition and GA3 Concentration}

\author{
Tatiek Kartika Suharsi* dan Namira Andiani
}

${ }^{1}$ Departemen Agronomi dan Hortikultura, Fakultas Pertanian, Institut Pertanian Bogor (Bogor Agricultural University), Jl. Meranti, Kampus IPB Darmaga, Bogor 16680, Indonesia Telp.\&Faks.62-251-8629353 e-mail agronipb@indo.net.id

\begin{abstract}
The objectives of this research was to know the effect of growing media composition and concentration level of GA3, on growth of Sansevieria trifaciata Prain 'Laurentii' shoots. The research was conducted at Leuwikopo Experiment Field, IPB, Darmaga from March until July 2011. The research used Randomized Complete Block Design (RCBD) with two factors and three replications, Sansevieria trifaciata Prain 'Laurentii'variegata leafs used in this research. The first factor was growing medium composition, they were charcoal husk: soil: compos (1:2:1); pasir malang: soil: compos (2:2:1); cocopeat: soil: compos (3:2:1). The second factor was concentration of GA3 treatment consist of three level, 0 ppm; 100 ppm : 500 ppm. Charcoal husk and pasir malang gave good effect for growth of young shoots. Concentration of GA3 until 500 ppm had no significant effect on young shoot growth but it had significant effect on roots growth. The best interaction treatment effect on young shoots growth was charcoal husk medium and 500 ppm concentration of GA3.
\end{abstract}

Keywords: charcoal husk, cocopeat, leaf cutting, pasir malang

\section{ABSTRAK}

Tujuan penelitian ini untuk mengetahui pengaruh komposisi media tanam dan konsentrasi GA3 terhadap inisiasi dan pertumbuhan tunas stek daun Sansevieria trifasciata Prain "Laurentii". Percobaan dilakukan di kebun percobaan IPB Leuwikopo, Darmaga mulai bulan Maret hingga Juli 2011. Menggunakan Rancangan Kelompok Lengkap Teracak (RKLT) dua faktor dan tiga ulangan. Sansevieria yang digunakan jenis daun variegata. Faktor pertama komposisi media tanam, tiga jenis : arang sekam:tanah:kompos (1:2:1), pasir malang: tanah:kompos (2:2:1), cocopeat:tanah:kompos (3:2:1). Konsentrasi GA3:0, 100, 500 ppm. Media arang sekam dan pasir malang baik untuk pertumbuhan tunas, konsentrasi GA3 hingga 500 ppm tidak berpengaruh terhadap pertumbuhan tunas tetapi berpengaruh terhadap pertumbuhan akar, perlakuan terbaik untuk pertumbuhan tunas Sansevieria trifasciata Prain "Laurentii" adalah media arang sekam dan GA3 500 ppm.

Kata kunci: arang sekam, cocopeat, stek daun, pasir malang

\section{PENDAHULUAN}

Sansevieria merupakan salah satu tanaman dari famili Agavaceae dan merupakan salah satu tanaman hias yang mampu menyerap polutan. Tanaman Sansevieria pada umumnya digunakan sebagai

\footnotetext{
* Penulis untuk korespondensi. e-mail: t.suharsi@yahoo.co.id
}

tanaman hias indoor dan tanaman lanskap, namun Sansevieria dapat pula dimanfaatkan sebagai tanaman obat, seratnya pun dapat digunakan sebagai bahan baku tekstil, tergantung dari jenis atau spesiesnya. Sansevieria memiliki nilai ekonomi yang cukup tinggi dan mempunyai prospek yang cukup bagus, karena telah menjadi salah satu komoditas eksport. Korea Selatan merupakan salah satu negara pengimpor 
Sansevieria (Direktorat Jendral Pengolahan dan Pemasaran Hasil Pertanian, 2010). Permintaan akan komoditas Sansevieria perlu diimbangi dengan teknik budidaya yang baik guna memenuhi permintaan pasar domestik dan internasional.

Perbanyakan Sansevieria pada umumnya dilakukan secara vegetatif, seperti: pisah anakan, stek daun, potong pucuk, cacah daun, cabut pucuk, stek rimpang, dan kultur jaringan (Purwanto, 2006). Perbanyakan secara vegetatif banyak dilakukan karena lebih cepat menghasilkan anakan dibandingkan perbanyakan secara generatif. Budidaya tanaman Sansevieria memerlukan komposisi media tanam yang cocok, sehingga dapat memberikan pertumbuhan yang baik. Penggunaan media tanam yang tepat bagi Sansevieria perlu diteliti sehingga dapat menghasilkan tanaman yang memiliki penampilan menarik dan pertumbuhan yang baik. Lingga (2005) menyatakan bahwa media tanam yang baik bagi Sansevieria adalah media yang bersifat porous, sedikit kandungan bahan organik dan tidak cepat melapuk. Pertumbuhan daun yang cenderung lambat pada Sansevieria terkadang menjadi kendala yang dialami para pebisnis dibidang tanaman hias daun yang memiliki banyak manfaat ini. Harjadi (2009) dan Wattimena (1988) menyatakan bahwa giberelin adalah suatu golongan ZPT dengan rangka ent-gibberellins yang berfungsi merangsang pembelahan sel, pemanjangan sel, dan fungsi pengaturan lain. Penggunaan komposisi media tanam yang sesuai serta aplikasi ZPT $\mathrm{GA}_{3}$ dengan konsentrasi yang tepat, diharapkan dapat menstimulasi pertumbuhan vegetatif tanaman Sansevieria, mengingat Sansevieria merupakan tanaman hias daun, maka pertumbuhan vegetatifnya lebih diutamakan dibandingkan pertumbuhan generatifnya.

Penelitian ini bertujuan untuk mengetahui komposisi media tanam yang sesuai, konsentrasi ZPT Giberelin $\left(\mathrm{GA}_{3}\right)$ dan interaksi antara komposisi media tanam dengan konsentrasi ZPT Giberelin $\left(\mathrm{GA}_{3}\right)$ untuk pertumbuhan tunas Sansivieria trifaciata Prain 'Laurentii' .

\section{BAHAN DAN METODE}

Penelitian dilaksanakan pada bulan Maret sampai dengan bulan Juli 2011, di Kebun Percobaan Leuwikopo IPB, Darmaga Bogor. Analisis media tanam dilakukan di Laboratorium Balai Penelitian Tanah Bogor.

Bahan tanaman yang digunakan adalah stek daun Sanseviera trifaciata Prain 'Laurentii' jenis daun variegata. Bahan lain yang digunakan adalah pupuk kandang, kompos, arang sekam, cocopeat, tanah, pasir malang, polibag; ZPT GA 3 , fungisida Dithane. Alat yang digunakan : rumah paranet dengan naungan 55\% berukuran $10 \mathrm{~m}$ x $5 \mathrm{~m}$ digunakan sebagai bangunan tanam, alat alat untuk menanan stek.

Penelitian terdiri dari dua bagian, bagian pertama adalah stimulasi pertumbuhan akar dan inisiasi tunas stek daun Sansevieria trifaciata Prain 'Laurentii'. Bagian kedua adalah percobaan untuk mengetahui pengaruh komposisi media tanam serta konsentrasi

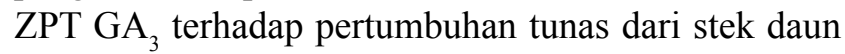
Sansevieria trifaciata Prain 'Laurentii'. Stek daun dari dua jenis Sansevieria trifaciata Prain'Laurentii' jenis daun variegata dan jenis daun hijau, ditanam untuk menumbuhkan tunasnya selama 13 minggu. Stek daun yang telah bertunas digunakan sebagai bahan untuk percobaan yang sebenarnya.

Rancangan yang digunakan dalam percobaan adalah Rancangan Kelompok Lengkap Teracak (RKLT) dua faktor. Faktor pertama adalah jenis komposisi media tanam dan faktor kedua adalah konsentrasi ZPT GA . Komposisi media tanam yang digunakan dalam percobaan terdiri dari tiga jenis yaitu (M1) arang sekam : tanah : kompos (1:2:1); (M2) pasir malang : tanah : kompos (2:2:1); (M3) cocopeat : tanah : kompos dengan perbandingan (3:2:1). Konsentrasi ZPT GA 3 yang digunakan terdiri dari tiga taraf yaitu (G0) konsentrasi 0 ppm, (G1) konsentrasi $100 \mathrm{ppm}$, (G2) konsentrasi $500 \mathrm{ppm}$. Data yang diperoleh dianalisis dengan menggunakan uji-F dan uji lanjut yang digunakan adalah uji wilayah berganda Duncan (DMRT) pada taraf 5\% apabila dalam uji-F menunjukkan pengaruh nyata.

Stimulasi pertumbuhan tunas dan akar stek daun dimulai dari penanaman bahan stek daun, hingga secara keseluruhan stek daun membentuk tunas pada 13 MST. Panjang bahan stek daun yang digunakan adalah $15 \mathrm{~cm}$. Bahan stek daun Sansevieria yang telah dipotong, pada bagian pangkal bahan stek diolesi dengan pasta zat perangsang pertumbuhan akar dengan dosis $10 \mathrm{~g}$ untuk 10 bahan stek, hal ini ditujukan untuk mempercepat pengakaran. Bahan stek kemudian dikering anginkan selama 2-3 menit. Stek-stek daun tersebut kemudian ditanam dalam polybag yang sudah diisi campuran media tanam pupuk kandang dan tanah dengan perbandingan 1:1 (v/v) sebagai media inisiasi pengakaran dan pertumbuhan tunas pada stek daun sansevieria. Bahan stek daun dibenamkan sekitar 1.5 $\mathrm{cm}$ pada campuran media pupuk kandang dan tanah. Stek daun sansevieria yang berusia sekitar 13 MST telah membentuk akar dan tunas, dilakukan pindah tanam kedalam polybag pada komposisi media perlakuan yaitu komposisi media M1, M2 dan M3. Aplikasi hormon Giberelin (ZPT $\mathrm{GA}_{3}$ ) 
dilakukan setelah stek daun sansevieria berada dalam media perlakuan. Aplikasi ZPT GA dilakukan setiap satu minggu sekali dengan cara menyemprotkan pada tunas muda dari stek daun sansevieria dengan konsentrasi 100 ppm untuk perlakuan G1 dan 500 ppm untuk perlakuan $\mathrm{G} 2$, dengan volume semprot $5 \mathrm{ml}$ dan diaplikasikan pada pagi hari. Pemeliharaan dilakukan dengan pengendalian gulma dilakukan secara manual yaitu dengan mencabut gulma yang ada disekitar polybag yang dilakukan tiap satu minggu sekali. Pengendalian hama dan penyakit dilakukan apabila terdapat sansevieria yang terserang hama atau terkena penyakit, pencegahan penyakit dilakukan dengan aplikasi fungisida Dithane setiap satu minggu sekali dengan dosis $2 \mathrm{mg} \mathrm{l}^{-1}$. Percobaan dilakukan hingga 21 MST.

Pengamatan pertumbuhan vegetatif stek daun meliputi: persentase stek hidup (\%), panjang akar $(\mathrm{cm})$, bobot basah akar (g), bobot kering akar (g), pertambahan tinggi tunas $(\mathrm{cm})$, tinggi tunas $(\mathrm{cm})$, jumlah tunas, jumlah daun, bobot basah tunas (g), bobot kering tunas $(\mathrm{g})$. Pengamatan terhadap keragaan meliputi : keragaan warna daun dan keragaan bentuk daun.

\section{HASIL DAN PEMBAHASAN}

Pengaruh Komposisi Media Tanam dan Konsentrasi


Sansevieria trifaciata Prain 'Laurentii' Jenis Daun Variegata

Berdasarkan hasil analisis ragam, interaksi antara faktor komposisi media tanam dan konsentrasi $\mathrm{GA}_{3}$ berpengaruh nyata hanya terhadap parameter pertambahan tinggi tunas pada 4 MSP. Faktor tunggal komposisi media tanam berpengaruh nyata hanya terhadap parameter tinggi tunas. Komposisi media tanam tidak berpengaruh nyata terhadap sebagian besar parameter pengamatan lain, hal ini diduga karena ketiga jenis komposisi media tanam memiliki kesamaan yaitu terdiri dari beberapa jenis media yang mengadung bahan organik dan anorganik serta baik untuk pertumbuhan tanaman pada umumnya. Sehingga pertumbuhan tunas yang dihasilkan dari stek daun Sansevieria trifaciata Prain 'Laurentii' jenis daun variegata pada ketiga jenis komposisi media tanam tidak berpengaruh nyata. Faktor tunggal konsentrasi ZPT $\mathrm{GA}_{3}$ berpengaruh nyata terhadap parameter bobot basah dan bobot kering akar. Diduga karena GA endogen dalam bahan stek sudah mencukupi untuk pertumbuhan tunas Sansevieria trifaciata Prain 'Laurentii', sehingga aplikasi GA secara eksogen yaitu dengan penambahan dua jenis taraf konsentrasi $\mathrm{GA}_{3}$, tidak memberikan pengaruh secara nyata.

Tabel 1 menunjukkan pertambahan tinggi tunas stek daun sansevieria jenis variegata yang mendapat perlakuan komposisi media tanam dan konsentrasi GA3 berbeda Perlakuan $\mathrm{GA}_{3}$ hingga 500 ppm dan M1 masih meningkatkan pertambahan tinggi tunas, namun pada M2 dan M3 ketiga konsentrasi GA 3 memberikan pertambahan tinggi tunas tidak berbeda. Perlakuan M3 dan ketiga konsentrasi $\mathrm{GA}_{3}$ memberikan pertambahan tinggi tunas yang terkecil dibanding kedua komposisi media lainnya.

Komposisi media M1 dan M2 diduga mempunyai aerasi lebih bagus dibanding M3. Aktifitas $\mathrm{GA}_{3}$ terutama memperpanjang ruas tanaman dengan bertambahnya ukuran dan jumlah sel pada ruas ruas tanaman (Wattimena, 1988). Penambahan $\mathrm{GA}_{3}$ konsentrasi 500 ppm diduga dapat menstimulasi pertambahan tinggi tunas stek daun.

Tabel 1. Pengaruh Interaksi Komposisi Media Tanam dan Konsentrasi GA 3 terhadap Pertambahan Tinggi Tunas Sansevieria trifaciata Prain 'Laurentii' Jenis Daun Variegata pada 4 MSP

\begin{tabular}{|c|c|c|c|c|c|}
\hline \multirow[t]{3}{*}{ Media Tanam } & \multicolumn{3}{|c|}{ Konsentrasi GA3 (ppm) } & \multirow[t]{3}{*}{ Rataan } & \multirow[t]{3}{*}{ KK } \\
\hline & G0 & G1 & G2 & & \\
\hline & 0 & -100 & -500 & & \\
\hline M1 & $1.76 \mathrm{bc}$ & $2.69 \mathrm{ab}$ & $3.14 \mathrm{a}$ & $2.53 \mathrm{~A}$ & 22.047 \\
\hline M2 & $2.97 \mathrm{a}$ & $2.81 \mathrm{a}$ & $2.32 \mathrm{abc}$ & $2.70 \mathrm{~A}$ & \\
\hline M3 & $1.49 \mathrm{c}$ & $2.35 \mathrm{abc}$ & $1.65 \mathrm{c}$ & $1.83 \mathrm{~B}$ & \\
\hline Rataan & 2.07 & 2.62 & 2.37 & & \\
\hline
\end{tabular}

Keterangan: Angka-angka yang diikuti huruf yang sama pada kolom dan baris yang sama tidak berbeda nyata pada uji uji jarak berganda Duncan (DMRT) pada taraf 5\%

M1 = Arang sekam : tanah $:$ kompos $(1: 2: 1)$

M2 = Pasir malang $:$ tanah $:$ kompos $(2: 2: 1)$

M3 = Cocopeat $:$ tanah $: \operatorname{kompos}(3: 2: 1)$ 
Berdasarkan data pada Tabel 2, stek yang ditanam pada komposisi media M1, cenderung menghasilkan persentase stek hidup, bobot basah dan bobot kering akar yang lebih tinggi dibandingkan komposisi media M2 dan M3. Rata-rata pertambahan tinggi tunas, jumlah tunas, bobot basah dan bobot kering tunas, serta jumlah daun tertinggi cenderung dihasilkan dari stek daun yang ditanam pada komposisi media M2.

Terlihat bahwa komposisi media M1 berpengaruh baik bagi parameter perakaran, sedangkan komposisi media M2 berpengaruh baik bagi parameter pertumbuhan tunas Sansevieria trifaciata Prain 'Laurentii' jenis daun variegata. Stek yang ditanam pada komposisi media M3 cenderung memberikan nilai terendah untuk semua parameter yang diamati, kecuali pada parameter panjang akar.

Diduga komposisi media M1dan M2 cukup porous dibandingkan dengan M3 sehinga dapat memicu pertumbuhan akar dan tunas lebih baik. Cavins et al. (2002) dalam Susilawati (2007) menyatakan bahwa nilai EC suatu larutan media diduga menyatakan status hara tanaman, semakin besar kandungan EC semakin mudah ion-ion bergerak melalui larutan. Semakin mudah ion-ion tersebut bergerak maka ketersediaanya semakin tinggi untuk tanaman sehingga tanaman mudah untuk menyerap ion-ion tersebut. Diduga nilai EC dari M1 dan M2 lebih besar dibanding M3. Pengaruh faktor tunggal konsentrasi $\mathrm{GA}_{3}$ terhadap parameter pertumbuhan tunas Sansevieria trifaciata Prain 'Laurentii' jenis daun variegata dicantumkan pada Tabel 3.

Tabel 3, penambahan ZPT GA 500 ppm nyata dapat meningkatkan bobot basah serta bobot kering akar dibandingkan dengan kontrol. Stek dengan penambahan $\mathrm{GA}_{3}$ dengan konsentrasi 500 ppm, menghasilkan bobot basah dan bobot kering akar tertinggi. Penambahan GA3 hingga 500 ppm diduga masih terjadi pembesaran dan pemanjangan sel dibagian akar, sehingga dapat meningkatkan bobotnya. Salisbury dan Ross (1995) menyatakan bahwa morfologi akar ditentukan oleh keadaan lingkungan media dan hara. Penambahan GA3 yang ditujukan untuk memicu pertambahan panjang tunas, juga mempengaruhi pertumbuhan akar stek.

Pemberian GA3 hingga 500 ppm tidak meningkatkan tinggi tunas secara nyata, namun bila diberikan perlakuan komposisi media tanam maka

Tabel 2. Pengaruh Faktor Tunggal Komposisi Media Tanam terhadap Pertumbuhan Tunas Sansevieria trifaciata Prain 'Laurentii' Jenis Daun Variegata

\begin{tabular}{lllll}
\hline Parameter & MSP & \multicolumn{3}{c}{ Komposisi Media } \\
\cline { 3 - 5 } & & \multicolumn{2}{c}{ M1 } & \multicolumn{2}{c}{ M3 } \\
\hline Pertambahan Tinggi Tunas (cm) & 1 & 1.96 & 1.94 & 2.34 \\
& 2 & 1.98 & 1.93 & 2.05 \\
& 3 & 2.24 & 2.29 & 1.71 \\
& 4 & $2.53 \mathrm{a}$ & $2.70 \mathrm{a}$ & $1.83 \mathrm{~b}$ \\
& 5 & 1.82 & 2.04 & 1.6 \\
& 6 & 1.5 & 1.56 & 1.31 \\
\hline \% Stek Hidup & Rataan & 2 & 2.08 & 1.81 \\
Panjang Akar (cm) & 7 & 88.89 & 88.22 & 84.44 \\
BB Akar (gr) & 7 & 11 & 11.72 & 12.5 \\
BK Akar (gr) & 7 & 4.73 & 4.41 & 4.3 \\
Jumlah Tunas & 7 & 0.86 & 0.8 & 0.76 \\
Tinggi Tunas (cm) & 7 & 1.4 & 1.58 & 1.44 \\
BB Tunas (gr) & 7 & $18.8 \mathrm{a}$ & $18.66 \mathrm{a}$ & $17.43 \mathrm{~b}$ \\
BK Tunas (gr) & 7 & 39.08 & 43.08 & 34.2 \\
Jumlah Daun & 7 & 3.43 & 3.92 & 3.39 \\
\hline
\end{tabular}

Keterangan: $\quad$ MSP = Minggu Setelah Perlakuan Angka-angka yang diikuti huruf yang sama pada kolom yang sama tidak berbeda nyata pada uji uji jarak berganda Duncan (DMRT) pada taraf 5\% 
Tabel 3. Pengaruh Faktor Tunggal Konsentrasi GA3 terhadap Pertumbuhan Tunas Sansevieria trifaciata Prain 'Laurentii' Jenis Daun Variegata

\begin{tabular}{|c|c|c|c|c|}
\hline \multirow[t]{2}{*}{ Parameter } & \multirow[t]{2}{*}{ MST } & \multicolumn{3}{|c|}{ Konsentrasi GA3 } \\
\hline & & G0 & G1 & G2 \\
\hline \multirow{7}{*}{$\begin{array}{l}\text { Pertambahan Tinggi } \\
\text { Tunas }(\mathrm{cm})\end{array}$} & 1 & 2.1 & 2.1 & 2.04 \\
\hline & 2 & 1.87 & 2.02 & 2.7 \\
\hline & 3 & 2.12 & 2.27 & 2.27 \\
\hline & 4 & 2.07 & 2.62 & 2.37 \\
\hline & 5 & 1.8 & 1.9 & 1.67 \\
\hline & 6 & 1.36 & 1.44 & 1.57 \\
\hline & Rataan & 1.89 & 2.05 & 2.1 \\
\hline \% Stek Hidup & 7 & 88.89 & 84.44 & 82.22 \\
\hline Panjang Akar (cm) & 7 & 11.64 & 11.96 & 11.62 \\
\hline BB Akar (gr) & 7 & $5.24 \mathrm{~b}$ & $6.50 \mathrm{ab}$ & $7.79 \mathrm{a}$ \\
\hline BK Akar (gr) & 7 & $0.66 \mathrm{~b}$ & $0.86 \mathrm{ab}$ & $0.91 \mathrm{a}$ \\
\hline Jumlah Tunas & 7 & 1.47 & 1.42 & 1.53 \\
\hline Tinggi Tunas $(\mathrm{cm})$ & 7 & 18.88 & 18.15 & 17.93 \\
\hline BB Tunas (gr) & 7 & 36.11 & 42.42 & 37.83 \\
\hline BK Tunas (gr) & 7 & 3.22 & 3.81 & 3.7 \\
\hline Jumlah Daun & 7 & 2.96 & 2.82 & 2.96 \\
\hline
\end{tabular}

Keterangan: $\quad$ Angka-angka yang diikuti huruf yang sama pada kolom yang sama tidak berbeda nyata pada uji uji jarak berganda Duncan (DMRT) pada taraf 5\%

G0 $=$ Konsentrasi GA sebesar 0 ppm

$\mathrm{G} 1=$ Konsentrasi $\mathrm{GA}_{3}$ sebesar $100 \mathrm{ppm}$

$\mathrm{G} 2=$ Konsentrasi $\mathrm{GA}_{3}$ sebesar $500 \mathrm{ppm}$

interaksi kedua perlakuan tersebut berpengaruh nyata terhadap pertumbuhan tunas stek daun Sansevieria trifasciata Prain "Lorentii" jenis daun variegata.

\section{KESIMPULAN}

Komposisi media arang sekam : tanah : kompos (1:2:1) dan komposisi media pasir malang : tanah : kompos $(2: 2: 1)$ merupakan media yang baik untuk menstimulasi pertumbuhan tunas pada Sansevieria trifasciata Prain "Laurentii" jenis variegata.

Penggunaan ZPT GA3 hingga konsentrasi 500 ppm tidak meningkatkan pertumbuhan tunas pada Sansevieria trifasciata Prain "Laurentii" jenis daun variegata, namun meningkatkan pertumbuhan akar stek.

Perlakuan komposisi media arang sekam :tanah: kompos (1:2:1) dan GA3 500 ppm paling bagus untuk stimulasi pertumbuhan tunas Sansevieria trifasciata Prain "Laurentii" jenis daun variegata.

\section{DAFTAR PUSTAKA}

Direktorat Jendral Pengolahan dan Pemasaran Hasil Pertanian. 2010. http://agribisnis.deptan.go.id. [16 Februari 2011]

Harjadi, S.S. 2009. Zat Pengatur Tumbuh Pengenalan dan Petunjuk Penggunaan pada Tanaman. Cetakan 1. Penebar Swadaya. Jakarta.

Lingga,L.2005. Panduan Praktis Budidaya Sansevieria. Cetakan 1. Agromedia Pustaka. Jakarta.

Purwanto, A.W. 2006. Sanseviera Flora Cantik Penyerap Racun. Kanisius. Yogyakarta.

Salisbury, F.B., Ross, C.W. 1995. Fisiologi Tumbuhan Jilid Tiga (diterjemahkan dari: Plant Physiology, penerjemah : D.R. Lukman dan Sumaryono). ITB. Bandung.

Susilawati, E. 2007. Pengaruh komposisi media terhadap perkecambahan dan pertumbuhan tanaman Zinnia elegans dan Helichrysum bracteatum. Skripsi. Departemen Agronomi dan Hortikultura. Fakultas Pertanian. Institut Pertanian Bogor. Bogor.

Wattimena, G.A. 1988. Zat Pengatur Tumbuh Tanaman. Pusat Antar Universitas dan Lembaga Sumberdaya Informasi IPB. Bogor. 